\title{
BLENDED LEARNING IN THE INTRODUCTORY COMPUTER SKILLS COURSE
}

\author{
Paul R. Stephens, Bradley University,prs@bradley.edu \\ Matthew K. McGowan, BradleyUniversity, mmcgowan@bradley.edu \\ ValerieV. Pape, Bradley University, vpape@bradley.edu
}

\begin{abstract}
Can an introductory productivity software course be effectively taught through a blended and flipped course design? We review three recent studies using similar course designs and subject matter. Our data and analysis extends the understanding of whether this type of course design can increase learning effectiveness. The study examines a variety of data by capturing objective results such as homework and exam scores as well as student-reported use of various engagement activities (face-to-face class activities, video recording of class, short online help videos and open lab) over the length of the course. Additionally, we examine demographic data including student experience prior to the course. We find that learning effectiveness (as measured by exam grades) is a function of class engagement and specific characteristics of student experience. These findings allow us to predict student learning success using two separate models: (1) the class engagement model to predict homework success and (2) the positive experience model to predict exam success.
\end{abstract}

Keywords: Blended Learning, Flipped Classroom, Pedagogy, Spreadsheet Skills

\section{INTRODUCTION}

Increased pressure to offer courses online at universities and colleges across the county has motivated instructors to experiment with course designs that could be taught in online environments $[1,4,7]$. Some instructors are jumping directly into the online world [9], while others are transitioning their course design over time to work in an online setting [3]. We are also interested in the possibility of offering our introductory information systems and business applications course as an online course. This is a standard introductory spreadsheet and database applications course for freshman or sophomore business majors. Offering a tools course in an online environment creates unique challenges for the instructor [5], so we decided to slowly phase in our course design to discover the challenges for ourselves and those roadblocks that might be unique to our environment. We created a blended and flipped course design where students could (except for exams) never need to attend class. And, as a pedagogical experiment, we allowed students in two sections to choose how they wanted to take the course. A student could treat the course as an on-line course, never attend class and never meet face-to-face with the instructor (except for exams). Or, the students could decide how much face-to-face interaction they wanted. Additionally, we reviewed the literature for similar courses that had been converted by blending and flipping. From this, we discovered three published studies that provided us with benchmarks for comparison $[2,3,6]$. We have collected data on the choices that students made, their perceptions of the course and their performance. This paper attempts to illustrate and test those elements of blended tools course that lead to student success (or failure).

\section{Different Learning Experiences Defined}

There are many new approaches to pedagogy that have been driven by technology that have led to the ability to design courses as, hybrid, blended, inverted or even flipped. For the convenience of the reader and to better understand the context of the research, this section of the paper will begin by defining the learning experience approach of the course studied for this research. Margulieux, et al., [7] provide us with a valuable resource in understanding the differences between the various approaches. The authors argue that often researchers use the terms hybrid and blended in substitution while others do not. The term flipped is used as an alternative for the term inverted in some literature. The use of these terms makes it difficult for investigators and practitioners to use the research to compare findings, conduct additional research and apply the results to relevant situations.

Margulieux et al [7] delivered the Learning Experiences Taxonomy to help us dispel such inconsistencies amongst researchers. Two dimensions were identified as most critical to the taxonomy: delivery medium and instruction type. These two dimensions are crossed to form the taxonomy and are further refined to form the Combined Learning 
Experiences Taxonomy. The learning experience approach used for this study falls directly in the middle of the taxonomy and is defined by the authors as a blended learning experience. This method uses a "substantial portion (between $25 \%$ and $75 \%$ ) of delivery via an instructor, delivery via technology, information transmission and praxis." A flipped classroom is generally described as a form of blended learning and the term flipped is more commonly used than inverted. This study falls squarely into the category of a flipped and blended learning experience.

\section{USING A FLIPPED CLASSROOM TO TEACH SPREADSHEET SKILLS: THREE STUDIES}

The first study we reviewed was by Davies, Dean and Ball [2]. The authors flipped and blended a course similar to the course in our study. They were interested in discovering if the new design would increase student achievement in and satisfaction with the course. The purpose of their research was to "examine the effectiveness and feasibility of flipping a college course designed to teach introductory spreadsheet skills when compared to the traditional classroom approach."

The authors asked and attempted to answer four research questions: (1) Does the instructional approach impact learning effectiveness? (student achievement in the course), (2) How much did students perceive they learned?, (3) How much value did they attribute to the course?, and (4) Did the course impact their attitudes towards the course and the topic?

The study used a pretest/posttest experimental design with a multi-case comparative approach to the data analysis. Their experiment was based on three treatments: (1) traditional class based instruction, (2) independent study using MyITLab (environment which they called simulation) and (3) independent study using MYITLab before class followed by in class application (flipped and blended environment). The study's third treatment was similar to our design and delivery. Materials to support the class were online but not required. Class meetings were optional and designed to support work completed by students prior to class.

The results from the Davies et al [2] research found significant difference in learning (test scores) between the three treatments. The flipped and blended classroom resulted in better scores than either the traditional classroom (second best) or the simulation (worst results). But, the simulation is not of much interest in that it wasn't treated like an online option. Instead, it was a self-study option with a single means of learning support. As was noted by the authors, "motivational materials and additional problem-solving instruction were not provided." (p. 568) Students weren't allowed to attend class, grading was automated and although it doesn't explicitly state the following, it seems that instructor feedback was not provided nor were in-lab help hours made available. However, these students could visit the instructor during office hours.

Additional findings of the research centered on student perceptions of the three treatments. The authors used end of the course evaluations to compare the three treatments. Three elements from the course evaluations were captured: (1) overall evaluation of the course, (2) overall evaluation of the instructor and one evaluative statement (3) "I learned a lot taking this course." Not surprisingly, student perceptions of the simulation course were statistically significantly worse than the other two treatments. Otherwise, there wasn't a statistically significant difference between the flipped and blended course and the traditional course. Students were also asked to evaluate the value of the course based on three evaluative statements from the end of the semester course evaluation. Once again, students found the simulation course to be statistically less valuable than the other two treatments. And, once again, there were no statistically significant differences found between the traditional and flipped and blended course.

Lastly, the research looked at student reported time spent on learning activities and the value of these activities. The activities in this case amounted to (1) studying, (2) homework, and (3) getting help during office hours. Only around $36 \%$ of the students reported ever getting any help during office hours. And, according to the faculty, a significant portion of that time was not getting help but questioning how the automated grading system evaluated their assignments. Otherwise, there was little difference in the three treatments. As for the student perceived value of these activities, the simulation group reported statistically significantly lower value in all three activities. While the study found no statistically significant differences between the other two treatments.

So, what was the best argument for the blended and flipped classroom made by the researchers? It is both scalable and effective. In other words, the course can be delivered using fewer faculty resources without negatively impacting student learning. 
The second study we reviewed was by Larson and Yamamoto [6]. The research focuses on an experiment measuring the effectiveness of learning and student satisfaction of a college course teaching spreadsheet skills. The experimental group learned through a flipped classroom course design and the control group learned through a traditional face-to-face lecture/laboratory.

The authors identified three motivations for performing the experiment: measuring student satisfaction; providing the opportunity for instructors to teach at the application level rather than "how to" skills; and gathering evidence of whether flipping the classroom is effective for a spreadsheet skills course.

The study studied two sections of a flipped classroom (70 students) and two sections of a traditional face-to face classroom (55 students.) The course in both situations taught spreadsheet skills in the context software productivity learning objectives. The participants represented over 20 college majors, were self-selected, and typically freshman or sophomores. Gender statistics showed that $70 \%$ of the participants were male. The study used the same instructor and textbook for all four sections and collected data in each of those sections.

The traditional face-to-face classroom had demonstrations and explanations by the instructor and assigned homework for students to do on their own. The flipped classroom used video recordings provided by the textbook author to demonstrate techniques, concepts and skills. The flipped classroom provided opportunities to work together in the classroom on homework. Flipped classroom participants had the option to watch videos and to report to class to ask questions of the instructor and other classmates or complete the tasks on their own.

The research examined homework scores and compared the traditional lecture group and the flipped learning group to determine which method was most effective to teach the skills. The homework data was empirically tested. Initial empirical results showed no statistically significant difference in teaching effectiveness as measured by homework learning assessments. Given the post hoc computation of power, the results indicated a high probability for a Type II error and therefore a larger sample size indicated for future research.

The study also included a three-question survey to determine the students' preferences for a flipped classroom using both quantitative measurements and quantitative comments. Qualitative comments (and linkage to descriptive data) from students in the flipped class showed that students with prior knowledge of the software or those with quick learning ability did well on the learning assessment without watching the videos. Students with high self-efficacy liked self-directed learning and disliked in-class learning when the pace was too slow for them. The same qualitative data showed that students without prior knowledge or low levels of confidence did find benefit from watching instructional videos. The research concluded that instructors could refer to student prior knowledge and content difficulty in determining which portions of the learning objectives to use a flipped classroom.

The third research paper we found was published in a conference proceeding and mainly focused on descriptive results [3].

Frydenberg [3] used the flipped classroom approach for teaching the Excel portion of his first-year introductory Information Technology course. The course covers information technology concepts and Excel spreadsheet skills, with 10 of the 24 class sessions dealing with Excel. The flipped approach was used in three sections of the course taught by the same instructor: a day-time honors section, a day-time accelerated section, and an evening section.

Frydenberg [3] had student tutors in the CIS (Computer Information System) learning prepare short screen video recordings, seven to ten minutes in length, to demonstrate various spreadsheet concepts and skills. Students were required to watch the videos before class. At the start of each class, students took a brief quiz on the videos, and then worked on a group activity in class. Before the class was flipped, the instructor would explain concepts or demonstrate spreadsheet skills, and students would complete the mastery exercises from the textbook outside of class. The group activity involved teams of three students: one student would read the instructions for the task, another student would perform the task, and the third student would provide assistance to the student performing the task. For each class, students would take turns in each role.

Frydenberg [3] measured students' reactions to the flipped classroom sections, and reported the results using descriptive statistics. Students reported that they learned better when someone else explained the task to them, and agreed that alternating roles in the group exercises was an effective way to learn. Students also reported that they were able to help others in the group learn the material, and that this approach helped them connect with other 
students and have a more personal experience. Students generally reported that the flipped classroom helped them learn better than a traditional classroom, and that the videos were clear and short enough to convey a single concept.

\section{RESEARCH QUESTIONS}

The previous research that we studied represents attempts to blend and flip a learning experience. But, this previous research didn't take into account the theoretical work associated with student success in these environments. Instead, we would describe these efforts as exploratory and case oriented. As individual studies, they don't provide validation to theory or generalizable empirical findings. But, if we piece together these similar cases, we can start to get an idea of how blending and flipping a course in a particular environment might be successful and lead to a fully online course design. So, the main purpose of this paper is to provide an additional case of an attempt to blend and flip an introductory information systems and business applications course. Previous research [2] attempted to answer the following questions: (1) Does the instructional approach impact learning effectiveness? (student achievement in the course), (2) How much did students perceive they learned?, (3) How much value did they attribute to the course?, and (4) Did the course impact their attitudes towards the course and the topic? Our study focuses on the first question. Satisfaction and perceptions of value provide us some limited information about how students evaluate new learning environments. But, the real purpose of creating these learning experiences is to improve student achievement.

We conjectured that the quality of the instructional design and delivery will only be successful when the student understands and adheres to the intentioned learning environment created by such a design. Therefore, not only do we need to compare a traditional environment to the new design but we also need to understand how the new design leads to success or failure. So, we need to better understand the choices that students make and capture their activities throughout the semester. Some students will succeed and some students will fail. But why? Is it the learning environment or the behavior of the students in that learning environment? We suspected that it was a little of both. Additionally, we wanted to gather student feedback throughout the semester and not just at the end of the semester.

\section{PEDAGOGICAL DESIGN AND RESEARCH METHODOLOGY}

In the spring of 2015,52 students in two sections signed up for what they thought was the standard introductory information systems and business applications course required for all business students. The typical student in the study would be described as a traditional college student. These students are 18 to 21 years old $(86.5 \%$ are under $21)$, with little or no career related work experience. They are underclassmen ( $73.5 \%$ are freshmen or sophomores) and only $12 \%$ of the students are external transfers to the university.

On the first day of class, $100 \%$ of the students were in attendance and were informed that they had a choice about how they took the class. The student could treat the course like a traditional face-to-face course, or they could choose to treat the course as blended ( $25-75 \%$ face-to-face, $25-75 \%$ online) or they could treat the course as a fully technology mediated and delivered course (100\% online - except for exams). We would then capture the choices that students made about the course throughout the semester.

This required that the design and delivery needed to support both the face-to-face and technological needs of the students. The textbook used for the course is a comprehensive introduction to Excel. It is designed around tutorials that students can follow. We required that students complete these tutorials and turn them in for grading prior to class. Class time was then used to present the material in a different context and at a higher level which included troubleshooting, spreadsheet design, data analysis, interpretation and decision making. All the materials for class were posted online (both starting and finished files). Class activities were video recorded and posted online as well. Our expectations were that if the student chose not to attend class then they would use the recorded class activities as a surrogate for class attendance.

Weekly homework assignments were posted online. We treated the assignments as another learning experience for students. Therefore, we provided many opportunities for help and feedback from tutorials to homework and up to the exam associated with these materials. The exams were the students' opportunity to demonstrate what they had learned. Given that students had different choices, we had to provide help and feedback both online and face-toface. Online help and feedback was provided through e-mail, finished and correct tutorial files posted online, finished and correct homework files posted online, general feedback posted online, video recording of the 
homework review that was done in class, and individualized grading sheets which focused on areas of concern for each student. These grading sheets were posted in each student's online drop box. We also posted short (less than 10 minute) help videos online that could be used as a resource. These videos were organized by tutorial and allowed students to focus in on a particular topic covered in an otherwise comprehensive tutorial. In addition to online help, we provided the option for face-to-face help. We held five hours of open lab time each week in which the students could come to the lab for help and/or feedback. Individual appointments were also available. And 15-20 minutes of class time each week was dedicated to homework review. Once again, students could rely solely on online help and feedback, opt for a mix of the two or focus mainly on face-to-face help and feedback.

We surveyed the students three times throughout the semester about their choices and behavior (right after the first exam, immediately after the second exam and at the end of the semester). This allowed us to track changes in behavior/choices over time instead of just taking a snapshot approach at the end of the semester. Plus, we were able to capture data from students who eventually dropped the course. We also had student GPA and number of semester hours completed data. We used test results as our measure of student achievement.

\section{RESULTS}

Our expectations were that if students completed the designed learning experiences that it would lead to higher levels of achievement. But, we also wanted to explore. So, we included demographic variables like major, gender, GPA and college hours completed.

The exploratory analysis reveals weak correlations between achievement and major, gender, confidence at the beginning of class, class activity interaction (both F2F and Video), or F2F help in an open lab. But, we argue that class activity interaction and F2F/Video help should contribute to quality homework. This leads to a positive learning experience for the student.

But, what we found was that F2F help in the open lab has a non-linear relationship to achievement. If the student takes little advantage of F2F help, this hurts achievement. But, if the student is spending significant time in the lab, they might be using the instructor as a crutch instead of putting in the time to learn the material on their own. So, how a student uses F2F lab time would be a better predictor of achievement and might be correlated with total exam scores. Some of the better students didn't come to lab often but when they did it was because they were stuck on a particular problem or they wanted to review a mistake made on an assignment. The poorer students came to lab because they didn't prepare for the homework properly and were at a loss on how to begin working on the assignment. The scores we have for F2F lab time don't provide us with information about how that lab time was used. And, we believe that is why we can't include it in the model at this time.

Also, we noticed that the relationship between class activities and achievement was non-linear for the exams but not the homework. Students could have reported up to 65 occurrences of preparatory activities. The sweet spot seems to be around $30-39$ activities. This sweet spot seems to be where student achievement in terms of both homework scores and exams scores are highest. There were 25 in-class activities that were recorded on video. Students who didn't attend class, could follow along with the video on their own time. If the total number of recorded activities is less than 25 , then the student was skipping at least some in-class activities. But, if the number of recorded activities is greater than 25 , then the student is repeating the activity by perhaps both coming to class and watching the video of the class. Students also indicated how much time they spent with help videos that were prepared for the course and posted online. The highest score associated with the use of online help would be 15 . So, students could selfreport up to 65 occurrences for the entire semester. When we aggregate the use of class activities with the use of video help (a factor we are referring to as class engagement) and correlate this factor to homework scores, we find a moderately high correlation $(+.62)$. See table 1 below.

Table 1. Class Engagement Versus Average Homework Score

\begin{tabular}{|c|c|}
\hline $\begin{array}{c}\text { Class Activities + Video Help } \\
\text { (Aggregate Usage Score 0 - 65) }\end{array}$ & Avg. HW Score \\
\hline $5-9$ & $47.3 \%$ \\
\hline $10-14$ & $46.8 \%$ \\
\hline $15-19$ & $43.7 \%$ \\
\hline
\end{tabular}




\begin{tabular}{|l|l|}
\hline $20-24$ & $54.0 \%$ \\
\hline $25-29$ & $63.3 \%$ \\
\hline $30-34$ & $87.4 \%$ \\
\hline $35-39$ & $90.4 \%$ \\
\hline $40-44$ & $85.8 \%$ \\
\hline
\end{tabular}

But, when we repeat the correlation analysis with the exam scores, we find almost no correlation $(+.08)$. These rather odd and contradictory results are explained by one of the main weaknesses of the study, a relatively small sample size. Because, when we correlate homework and exam scores we once again find moderately high correlation (+.66). See tables 2 and 3 below.

Table 2. Class Engagement Versus Average Exam Scores

\begin{tabular}{|c|c|}
\hline $\begin{array}{c}\text { Class Activities + Video Help } \\
\text { (Aggregate Usage Score 0 - 65) }\end{array}$ & Avg. Exam Score \\
\hline $5-9$ & $76.8 \%$ \\
\hline $10-14$ & $72.3 \%$ \\
\hline $15-19$ & $73.5 \%$ \\
\hline $20-24$ & $83.0 \%$ \\
\hline $25-29$ & $75.7 \%$ \\
\hline $30-34$ & $83.5 \%$ \\
\hline $35-39$ & $88.3 \%$ \\
\hline $40-44$ & $75.2 \%$ \\
\hline
\end{tabular}

Table 3. Average Homework Scores Versus Average Exam Scores

\begin{tabular}{|c|c|}
\hline Avg HW Scores & Average Exam Score \\
\hline $45-50 \%$ & $47.4 \%$ \\
\hline $60-64.9 \%$ & $67.0 \%$ \\
\hline $65-69.9 \%$ & $77.3 \%$ \\
\hline $70-74.9 \%$ & $72.1 \%$ \\
\hline $75-79.9 \%$ & $72.8 \%$ \\
\hline $80-84.9 \%$ & $73.5 \%$ \\
\hline $85-89.9 \%$ & $80.9 \%$ \\
\hline $90-94.9 \%$ & $85.7 \%$ \\
\hline $95-100 \%$ & $87.7 \%$ \\
\hline
\end{tabular}

We would expect significant multicollinearity between class engagement and the homework quality if we were to include both in a predictive model of exam success. Whereas, what we might expect is a regression model where homework quality can be predicted by an aggregate measure of class activities and video help (class engagement).

Average Homework Score $(\mathrm{QHW})=\mathrm{F}$ (Participation in In-Class Activities; Use of Video Recorded In-Class Activities; Use of Online Help Videos). We would call this factor class engagement.

Our sample size is fairly small $(\mathrm{n}=48)$. We ran a regression analysis evaluating the relationship between class engagement and homework outcomes. The results are found on table 4. 
Table 4. Regression Results for the Relationship Between Class Engagement and Homework Outcomes

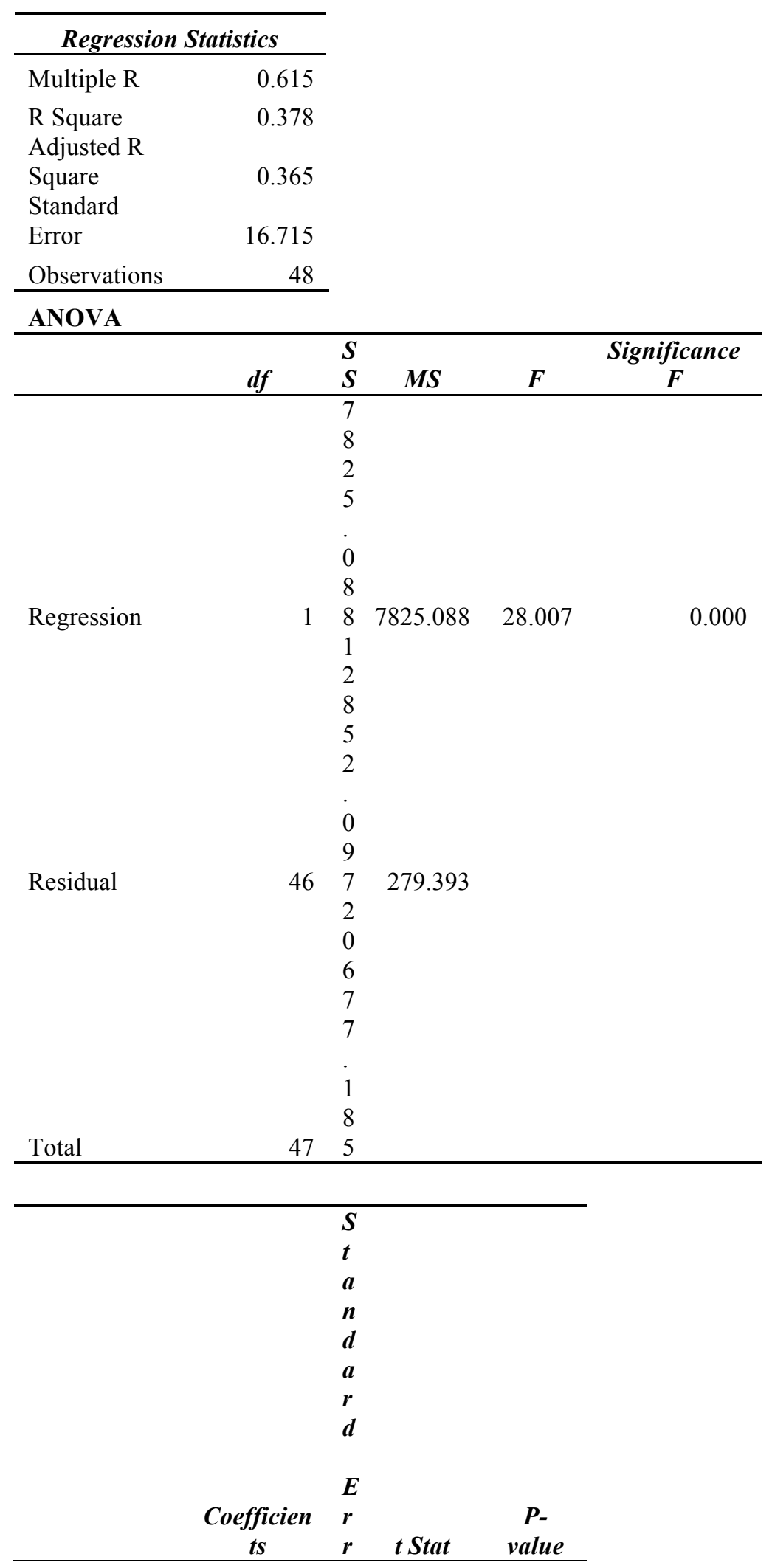




\begin{tabular}{|c|c|c|c|c|}
\hline & & $\begin{array}{l}\boldsymbol{o} \\
\boldsymbol{r}\end{array}$ & & \\
\hline \multirow{5}{*}{ Intercept } & \multirow{5}{*}{23.618} & 6 & \multirow{5}{*}{3.381} & \multirow{5}{*}{0.001} \\
\hline & & 9 & & \\
\hline & & 8 & & \\
\hline & & 5 & & \\
\hline & & 0 & & \\
\hline Class & & 2 & & \\
\hline Activities \& & & 6 & & \\
\hline Video Help & 1.404 & 5 & 5.292 & 0.000 \\
\hline
\end{tabular}

As you can see, the multi-construct factor (class engagement) is a significant predictor of quality homework. The activities and learning experiences designed and delivered for the blended course do result in better homework scores. Students can succeed in this learning environment when given choices. But, regardless of the learning environment, disengaged students will fail. We recognize that increased flexibility can lead to a higher potential for disengagement. Some students are well suited for the flexibility provided in this environment but others are not.

Our second model illustrates that such flexibility and choice is best suited for students with experience. Since the study was an exploratory, a variety of information was collected. Demographic data such as age, gender, major, type of major (quantitative/technical versus less quantitative/non-technical) and year in school were collected. Additionally, at the beginning of the course, subjects were asked to assess their confidence in learning and using Excel. But, in our exploratory regression modelling, these factors didn't contribute to predicting success in the class.

In the second model, homework quality is used in the model to predict exam achievement. Since the research is exploratory, we used a combination of correlation and regression analysis to identify those variables that best explain achievement through high exam scores. Our analysis revealed four variables that potentially strongly predict exam score success: Previous Experience w/ Excel, Grade Point Average, Completed College Hours and Homework Quality. When viewing the variables as a whole they pointed toward experience, particularly positive experiences which contribute toward achievement. Our exploratory analysis has revealed what we are calling the positive experience model.

\section{Characteristics of Experience (Correlation with Total Exam Scores)}

(1) Self-reported prior experience with Excel (PE) - (+.13)

(2) GPA coming into the course (GPA) - (+.51)

(3) Total College Experience (hours coming into the course) (HRS) - (+.25)

(4) Quality Homework (positive learning experience due to the use of class resources) (QHW) - (+.66)

Predicted Exam Scores $=$ PE + GPA + HRS + QHW $($ Correlation when Equally Weighted +.61$)$

The results of the regression analysis are shown on table 5 .

Table 5. Regression Results of the Positive Experience Model

\begin{tabular}{lr}
\hline \multicolumn{2}{c}{ Regression Statistics } \\
\hline Multiple R & 0.753 \\
R Square & 0.567 \\
Adjusted R Square & 0.527 \\
Standard Error & 26.910 \\
Observations & 48 \\
\hline
\end{tabular}


ANOVA

\begin{tabular}{lrrrrr}
\hline & $\boldsymbol{d}$ & & \multicolumn{1}{c}{$\boldsymbol{S}$} & \multicolumn{1}{c}{$\boldsymbol{M S}$} & \multicolumn{1}{c}{ S Significance } \\
\hline Regression & 4 & 40814.548 & 10203.637 & 14.090 & 0.000 \\
Residual & 43 & 31139.155 & 724.166 & & \\
Total & 47 & 71953.703 & & & \\
\hline
\end{tabular}

\begin{tabular}{lrrrc}
\hline & Coefficients & $\begin{array}{c}\text { Standard } \\
\text { Error }\end{array}$ & \multicolumn{1}{c}{ S Stat } & $\begin{array}{c}\boldsymbol{P} \text { value } \\
\text { valu }\end{array}$ \\
\hline Intercept & 14.960 & 30.605 & 0.489 & 0.627 \\
Prior Experience w/ Excel & 0.442 & 0.157 & 2.815 & 0.007 \\
GPA & 16.389 & 5.843 & 2.805 & 0.008 \\
Total Hours & 0.022 & 0.165 & 0.131 & 0.897 \\
Total Homework Scores & 1.984 & 0.426 & 4.651 & 0.000 \\
\hline
\end{tabular}

Total completed college credit (in hours) doesn't contribute to the model. But, the other variables that reveal previous positive experience (GPA and Prior Experience with Excel) do. Additionally, positive experience in class with homework assignments leads to better performance on exams.

\section{DISCUSSION}

We assert that the primary purpose of using alternative methods of course design is to improved student achievement. Student perceptions of value and student satisfaction are secondary aspects of understanding new learning experiences. The previous work that we have reviewed found that students liked blended and flipped courses but there was no indication that they performed better in this new environment. So, why bother? Our paper illustrates that success in these environments is a mixed bag. The learning experience works for some students leading to achievement while it fails for others leading to withdrawal or low grades. We need to better understand how these blended learning environments can contribute to student achievement. Policies that over or under generalize about students in these environments will only frustrate students. For example, a school might not allow students with fewer than 30 hours of credit to take online courses while there are students in that category that could successfully complete such classes. Or a school could convert a program to all online courses without considering the impact on student achievement.

Not surprisingly, persevering and doing the required work leads to achievement. Students would benefit from a decision model that would help them choose the best learning experience for them. Secondly, materials should be available to students to orient them to the learning experience [10]. Our research provides empirical support for these tactics that are seemingly not widely followed today.

Interestingly, as attendance of in-class activities and the viewing of the videos of those in-class activities both dropped toward the end of the semester, students began to flock to the F2F lab for help. This isn't surprising as students who stop preparing for the homework, struggle when they have to then complete the homework. We believe that this is simply students performing portfolio management. As the end of the semester comes into view, the deadlines increase and students must find a way to manage all of the deadlines and prepare for final exams. So, they cutout preparation and look to the instructor for more help so that their grades don't suffer. We don't see this as a practice associated with the blended and flipped learning environment. Instead, it is a common practice amongst college students in all learning environments.

\section{LIMITATIONS OF THE EXPLORATORY STUDY}

This study had a very small sample size which limited our use of statistical inference. A larger sample size should be built for further analysis. The students in the sample were almost exclusively traditional college students. We 
would expect significantly different results when studying more non-traditional college students. Factors such as student self-motivation and the ability to work independently should have a significant impact on success in the class.

This study relies on data reported by students. It assumes that the data is mainly valid and reliable. But, we know that this is not always true. When checking self-reported attendance against actual attendance, we found discrepancies after the first exam. The design of future data collection should account for such potential inaccuracies.

Students were unaware when then registered for the course that they would be offered the choice to treat the class as a blended design. This could have introduced some confusion to the student, which could have been reflected in some of the performance results. On the other hand, our method prevented the students from self-selecting into a learning experience that they would normally avoid or go out of their way to choose. The sample may be better representation of the student population as a whole.

\section{FUTURE RESEARCH}

We cannot generalize our findings from this research to every blended or flipped experience, but some areas of additional research and analysis could help explain the phenomena that we captured. Conducting empirical tests for differences in learning effectiveness outcomes and student perceptions of satisfaction and value could be done using demographic characteristics. Of particular interest are college major, gender, and age. Additional analysis could be conducted using information about students' high school or previous experience with online learning (e.g. blended, flipped, fully-online) and students' academic achievement in high school or early college. We would expect that students with a previous high level of academic achievement would have gained the requisite skills needed for online learning success.

As the students were tracked and surveyed throughout the course and not just at its completion, it would be interesting to analyze if, how, and why students changed their choices to use specific course design elements in the learning process. (i.e. attend class, watch lecture videos, read textbook and complete tutorials, review short help videos, complete homework, get help at open lab, and incorporate instructor feedback.) These same choices could be linked to changes in learning effectiveness outcomes and student satisfaction measurements. To the extent that students stayed with or changed their usage of the elements of the blended course, it would help inform changes to future course designs. Furthermore, it would indicate whether students need additional coaching or modeling to determine the most effective way to utilize and sequence blended course materials.

Additional attitudinal and motivational information would also contribute to further research in this area. Understanding students' need for and preferred type and timing of intrinsic rewards would be helpful in understanding which parts of the course design are effective and which parts would benefit from redesign. Adding students' self-efficacy (computer skills and computational) could help us explain and predict whether students are successful in choosing the various course resources or whether the course design should direct additional face-toface checkpoints in the course design.

Another factor that could be examined is the organizational culture of the university or college. In our study, the students enrolled at an institution that specifically promoted a learning environment of "frequent student and faculty interaction" as well as "personalized experiences." To the extent that these students chose a college based on the their preference for these differentiating cultural norms, it may influence their preference for and ability to engage in the amount of self-directed learning that occurs in a blended and flipped course.

\section{REFERENCES}

1. Allen, I. E., \& Seaman, J. (2014). Grade Change: Tracking Online Education in the United States. Babson Park, MA: Babson Survey Research Group.

2. Davies, R., Dean, D., \& Ball, N. (2013). Flipping the classroom and instructional technology integration in a college-level information systems spreadsheet course. Educational Technology Research \& Development, 61(4), 563-580.

3. Frydenberg, M. (2013). Flipping Excel. Information Systems Education Journal, 11(1), 63-73. 
4. Heather, G. C., \& Lynda, R. W. (2012). Effective online instruction in higher education. Quarterly Review of Distance Education, 13(1), 11-14.

5. Khan, Z. R. (2014). Using Innovative Tools to Teach Computer Application to Business Students--A Hawthorne Effect or Successful Implementation Here to Stay. Journal Of University Teaching And Learning Practice [online], 11(1), 1-11. Available:http://ro.uow.edu.au/jutlp/vol11/iss1/6

6. Larson, S. \& Yamamoto, J. (2013). Flipping the College Spreadsheet Skills Classroom: Initial Empirical Results. Journal of Emerging Trends in Computing and Informational Sciences, 4(10), 751-758.

7. Margulieux, L. E., Bujak, K. R., McCracken, W. M., and Majerich, D. M. (2014, January). Hybrid, Blended, Flipped, and Inverted: Defining Terms in a Two Dimensional Taxonomy. Paper accepted to the 12th Annual Hawaii International Conference on Education, Honolulu, HI, January 5-9.

8. Napier, N. P., Dekhane, S., \& Smith, S. (2011). Transitioning to Blended Learning: Understanding Student and Faculty Perceptions. Journal Of Asynchronous Learning Networks, 15(1), 20-32.

9. Ruth, L. (2006). Converting My Course Converted Me: How Reinventing an On-Campus Course for an Online Environment Reinvigorated My Teaching. Teaching Theology \& Religion, 9(4), 236-242.

10. Shelton, K. \& Saltsman, G. (2005). Online Student Success (Chapter 6). From An Administrators Guide to Online Education. Sloan Consortium. Information Age Publishing. pp. $105-115$. 